\title{
A Study of the Publication pattern in CSIR-Plant Genetic Resources Research Institute
}

\author{
P. S. OSEI-KOFI*, L. M. ABOAGYE, S. BEKOE, L. DZANDU , \& L. D. ACHEAMPONG \\ (P. S. O. \& L. M. A.: CSIR-Plant Genetic Resources Research Institute; S. B. \& L. D.: CSIR-Insti- \\ tute of Scientific and Technological Information; L. D. A.: CSIR-Crop Research Institute) \\ *Corresponding author's e-mail address: oseikofips@gmail.com
}

\begin{abstract}
Plant genetic resources (PGR) are those resources that are of benefit to man. They are plant materials containing useful characters of actual or potential values. They are the basic raw materials for crop improvement today and for the future. This paper analysed changes in publication trend by scientists from 1981 to 2015 at the CSIR-Plant Genetic Resources Research Institute. It investigated major commodities covered by the articles produced by scientists of the Institute. The main area of study included publication formats covered by the articles in the Plant Genetic Resources Research Institute Reference (PGRRIREF Directory) (1981-2015). The study also highlighted recent research and development activities in each publication discipline in the PGRRIREF Directory. It is believed that information gathered from the analysis of this research, would increase the utilization of the crop plants in Ghana and beyond. Content analysis method and interviews were used for the study of the Publication pattern in CSIR-Plant Genetic Resources Research Institute. The findings indicated among others that, socio-economic $(27.2 \%)$, horticulture $(21.5 \%)$, root and tubers $(18.5 \%)$ recorded increasing publication disciplines. Technologies developed in these publication disciplines could be put on-line for a wider audience to enhance efficient conservation and utilization of plant genetic resources materials.
\end{abstract}

Keywords: CSIR-Plant Genetic Resources Research Institute; publication pattern; disciplineformats; research activities

Research and development notes. Received 5 Apr 17, revised 27 Feb 19

\section{Introduction}

According to Hassan et al., (2012), bibliometric studies assist in identifying areas of weakness and providing new insights into research and publications, to build on a solid foundation of past research work. It can also contribute greatly to the collection development activities of various institutions. Given the increasing levels in the publication of scientific papers, current reviews of the literature require awareness not just of the overall direction and achievements of a field of inquiry, but also of the latest studies (Pautasso, 2013). There are different categories of publications. Depending on the stage of the research, one result may be more appropriate than another for the work and could be used to evaluate the message one wants to communicate. The first decision one has to take in publishing a paper is whether to submit it as, an article to a journal, consultancy report, technical report, handbook, thesis, magazine, or to present it at a conference instead.

Ghana Jnl Agric. Sci. 54 (1), 56 - 66

GJAS is an Open Access Journal and distributed under the terms of the Creative Commons (CC) License [CC BY 4.0] 
The main reason of Piyush, (2012) working paper series of the India Institute of Management, Ahmedabad, was to help faculty members, research staff and doctoral students to speedily share their research findings with professional colleagues and test their research findings at the prepublication stage. That paper attempted to enumerate the issues and concerns in the Horticulture sector of India. However, Osei-Kofi (2015a) worked on the framework for the production of the five journals in the Council for Scientific and Industrial Research (CSIR). He investigated the major subject research areas covered by the articles in the journals. That study highlighted the role of the CSIR as a publisher in ensuring sustainability, visibility and dissemination of the journals.

A recent study by Gautam and Mishra, (2015), sought to describe and analyse scholarly research publications of Banaras Hindu University, Varanasi, India. In that research, 1041 articles were collected from Indian Citation Index from 2004 to 2013. The result obtained indicated that the research productivity of Banaras Hindu University was increasing at the average rate of 104.1 publications per year. Most of the research articles were contributed by joint authors. For instance, 404 articles were published in SCIE indexed journals while 637 articles were published in non-SCIE-indexed journals. The increase in publication pattern in Banaras Hindu University, Varanasi, India was higher than that of the CSIR-PGRRI due to high thesis generated by students. Thus the publication per year of CSIR-PGRRI is far below Banaras Hindu University, Varanasi, India. The outcome of this study is expected to motivate institutes with less published articles to increase their publications.

The best criterion for evaluating research institution is the quantity and quality of published research work. Articles are the most important source of scholarly publications. Articles convey current information to facilitate research, teaching and learning as well as knowledge dissemination. One of the most important means of exchanging the results of research activities is through the publication of articles.

Articles continue to play a pivotal role in the communication of primary research findings. (El-Maamiry \& Ghauri, 2013). Article publishing enables research findings of scholars to cross international boundaries to provide strong, positive connections between individual scholars, institutions and nations. In effect, publishing has always been valued, both in itself and for career development. Joe-Mensah and Bekoe (2010) asserted that there is greater pressure on researchers to report their research findings as articles in reputable journals. Getting the reports published in peer-reviewed articles is a great way of teaching new professionals at a college or university to gain recognition and standing with peers within their field.

The most common method of scholarly communication is by writing up the findings of research into an article (Alemna, 1994a). Published articles are one of the criteria for assessment for promotion in academia. They are the most important criterion for judging research success. Based on the report from the Council for Scientific and Industrial Research (CSIR) 248 ${ }^{\text {th }}$ Directors Management Committee meeting, CSIR-Plant Genetic Resources Research Institute was ranked low partly on account of limited research publications. The ranking of corporate CSIR was also low. By this ranking, therefore, Corporate CSIR and PGRRI have low research base since little article publications have come from researchers at these institutes. 
The goal of the CSIR-PGRRI is to ensure effective conservation and use of PGR, for food security and sustainable agricultural development. The results of these activities are to be published through an outlet for research. To safeguard the activities of the researchers in the CSIR-PGRRI, a comprehensive study of articles in various subject disciplines must be studied to enable staff to publish their research output online in order to increase their global visibility.

In a journal article, clear conclusions can be made and firmly supported by the data available. There are different kinds of journals produced in the world, scholarly and scientific. Some of these journals are; general journals, specialized journals, regional journals, institutional and scholarly journals, (Kevin, 2008; Murison \& Webb, 1991a; Harms et al., 2004). The general objective of this study was to assess the publication patterns and investigate the major commodity discipline researched into by staff of CSIR-Plant Genetic Resources Research Institute (CSIR- PGRRI).

\section{Materials and Methods}

Content analysis and in-depth interview sessions with selected scientists of the Institute were used for the study. Content analysis is the study of recorded information which has been recorded in texts, media, or physical items. It is the systematic reading of a body of texts, images, and symbolic matter, not necessarily from an author's or user's perspective, (Krippendorff, 2004). This method was used to examine patterns of communication in a replicable and systematic manner. The method adopted in analysing the cumulative literary output on Plant Genetic Resource (PGR) literature on Ghana was similar to that used by Harande and Ibrahim, (2014). Alemna (1994b), Fosu and Alemna (2002), Sam (2008) and Osei-Kofi (2015b) in their investigations, used bibliographies on PGR literature in Ghana. The data analysis method used in solving the problem under investigation were univariate and multivariate content data analysis. Quantitative content analyses were carried out on 232 articles of 11 publication formats namely: consultancy report, conference papers, directory, fliers, journals, manuals, newsletter, notes, technical report and thesis. Microsoft Excel software package version 2010 was used in determining the publication discipline.

The entries were analysed by years and then cumulated into a decade. The analysis took the form of the number of publications, the format of publications and subject covered. At the end of the data collection period the content analysis was made on 232 scientific and technical publications of staff of CSIR-PGRRI covering the period 1981-2015. The study on the publication formats covered publications from the six divisions in the CSIR-PGRRI namely: Plant Genetic Conservation Division, Plant Genetic Diversity Division, Plant Protection Divisions, Commercialisation and Information Division, and Administration and Finance Division. From the data recorded, conference papers had 37 articles, consultancies-two reports, directory one, fliers-seven, handbooks and manuals-eight articles, newsletters-10, notesfour, refereed journals-73 articles, technical reports-64 and thesis-14 articles. Bibliographic data of all the publication formats under study was assembled to facilitate the content analysis of the scholarly articles in the CSIR-PGRRI.

Discussions and consultations with experts in the field, colleagues and members of the CSIR-PGRRI were involved in analysing the bibliographic data. The number of authors, titles, and major publication disciplines of each 
publication format under investigation were all tallied to facilitate the analysis of the research. Data collected were analysed using tables and graphs to group number of publication formats and major commodity disciplines to establish and interpret the percentages obtained. This was done to enable the researchers identify the fewer research areas where much resources should be given. The Microsoft Excel software package version 2010 was used in the analysis of the data.

\section{Results and Discussions}

Table 1 shows the publication formats and major commodities covered by articles. The first three highest publication formats were recorded by Journals, technical reports and conference papers. Refereed journal paper recorded 73 articles, the highest in the PGRRIREF Directory. The study on refereed Journal Papers ranged from $4.1 \%$ on cereals and legumes to $26 \%$ on cereals alone.

Technical reports and unedited conference papers covered the period 1979 to 2015. This indicated a total of 64 articles, the second-highest publication format in the PGRRIREF Directory. Horticulture recorded 25\% resulting in 15.2 times the contributions of investigations in the biodiversity of $1.6 \%$. The recent Technical report published was on In-vitro establishment of Cryptolepis sanguinolenta (Bissah, 2015). Edited Conference Papers totalled 37 articles. The publication discipline ranged from $2.6 \%$ article on biotechnology to $42 \%$ articles on root and tubers. The recent conference paper was presented by Rudebjer et al. (2012) on the topic, 'Beyond commodity crop: Strengthening young scientists' capacity for research on underutilized species in Sub-Saharan Africa.

The least publication format-1 was on directory and fliers that are made up of a compilation of title and analysis of scientific and technical publications on plant genetic resources from CSIR-Plant Genetic Resources Research Institutes. The PGRRIREF Directory consists of ten publication formats, namely: Consultancy report, Conference papers, Fliers, Handbooks, Manuals, Newsletters, Journals, Technical report, Notes, and Theses (Osei-Kofi, 2015b; Aboagye, 2001).

TABLE 1

Publication formats and major commodities covered by articles

\begin{tabular}{lcccccccc}
\hline Publication format & Hort & Soc & $\boldsymbol{C}$ & $\boldsymbol{L}$ & $\boldsymbol{C} \boldsymbol{\&} \boldsymbol{L}$ & Biov & $\boldsymbol{R} \boldsymbol{\&} \boldsymbol{T}$ & Totals \\
\hline Consultancy report & 0 & 2 & 0 & 0 & 0 & 0 & 0 & $\mathbf{2}$ \\
Thesis & 4 & 5 & 3 & 2 & 0 & 0 & 0 & $\mathbf{1 4}$ \\
Manual & 0 & 0 & 1 & 0 & 1 & 0 & 6 & $\mathbf{8}$ \\
Directory & 0 & 1 & 0 & 0 & 0 & 0 & 0 & $\mathbf{1}$ \\
Fliers & 0 & 7 & 0 & 0 & 0 & 0 & 0 & 7 \\
Notes & 0 & 4 & 0 & 0 & 0 & 0 & 0 & $\mathbf{4}$ \\
Handbook & 8 & 2 & 1 & 0 & 0 & 0 & 1 & $\mathbf{1 2}$ \\
Technical Report & 20 & 11 & 6 & 1 & 0 & 12 & 14 & $\mathbf{6 4}$ \\
Conference Papers & 0 & 9 & 3 & 6 & 2 & 1 & 16 & $\mathbf{3 7}$
\end{tabular}




\begin{tabular}{lcccccccc} 
Newsletter & 2 & 4 & 0 & 1 & 3 & 0 & 0 & $\mathbf{1 0}$ \\
Journals & 16 & 18 & 19 & 11 & 3 & 0 & 6 & $\mathbf{7 3}$ \\
Totals & $\mathbf{5 0}$ & $\mathbf{6 3}$ & $\mathbf{3 3}$ & $\mathbf{2 1}$ & $\mathbf{9}$ & $\mathbf{1 3}$ & $\mathbf{4 3}$ & $\mathbf{2 3 2}$ \\
\hline
\end{tabular}

*Hort-Horticulture, Soc-Socio-economics, C-Cereals, L-legumes, Biov-Biodiversity, R \& T-Root and tubers

The findings from the research on the major subject covered by the articles in the CSIR-PGRRI staff publications revealed that socio-economics recorded $27.2 \%$, horticulture, $21.5 \%$ and root and tubers $18.5 \%$. These are the first three highest publication disciplines recorded as shown in Fig. 1. This meant that technologies developed in these publication disciplines and formats could be put on an online platform for a wider audience in addition to being efficient conservation and utilization of plant genetic resources materials. The findings can assist other agriculture-based research institutes of the CSIR to enhance scientific and technological output. Researchers get to know what colleagues are doing and forge to come out with a joint proposal to attract funding. The study determines staff strength and expertise in the major commodity discipline that is likely to lead to the mentoring of young scientists. Experienced scientists will assist young scientists to research into less thematic areas such as cereals, legumes and other biodiversity crops.

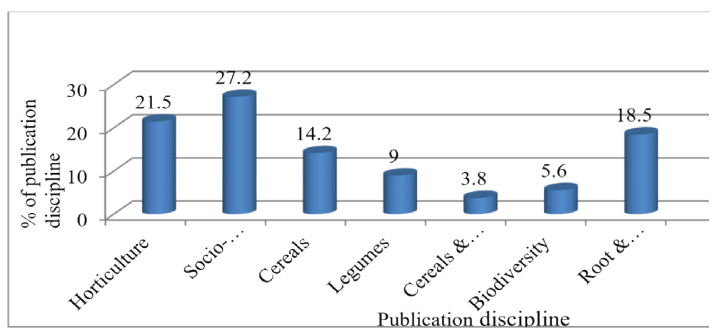

Fig. 1: Majour commodity covered (1981-2015)
Collaboration among Agricultural Institute of Canada (AIC), Canadian Society for Horticultural Science (CSHS) and Ghana Institute of Horticulturists (GhIH) had resulted into strengthening the institutional capacity of GhIH to serve as a credible authority for the promotion and development of horticulture in the economy of Ghana. The collaboration had built the capacity of farmers and improve their competitiveness in the vegetable value chain through farmer field schools and Training of Trainers workshops. For instance, introducing orange and sweet potato production as an intervention to perennial household food shortages had improved food and nutrition security in Ghana (Final Report for the AIC, 2015).

A partnership between GhIH and CSHS was established in 2001 with the initiation of a project that had strengthened the capacity of GhIH to serve as the key organization in Ghana with expertise in the development of the horticulture industry and enhance the production of vegetables. These achievements were realised through the use of irrigation and hand-dug wells in Nandom to increase the availability of more nutritious food and supplement incomes of villagers in the Upper West Region of Ghana. During the project, several objectives were achieved and many valuable lessons were learned. Membership of GhIH increased from all parts of the country and are currently becoming influential as credible authorities on horticultural issues and policy. 
There are additional opportunities for multinational investors to expand the horticulture sector, given Ghana's established market presence in Europe and favourable geographical position, to raise export revenues. Additional agro-processing, especially in the horticulture sector, can provide alternative markets to local production that is unable to meet European requirements and create jobs. A very important outcome was the establishment of a scientific horticulture journal by name 'Ghana Journal of Horticulture' (Final Report for the AIC, 2015).

The CSIR and Ministry of Food and Agriculture (MOFA) were highly praised for their collaborative efforts in the agricultural sector as well as the opportunity for stakeholders to share ideas, knowledge and experience in the root and tuber sector, (WAAPP International Root and Tuber Crops Conference, 2011). Salifu (2011) emphasized the contribution of CSIR Research Institutes to the socio-economic and industrial development including food security and poverty reduction in Ghana during WAAPP International Root and Tuber Crops Conference. That paper highlighted the advantages of root and tuber crops over the grain crops. Had it not been the negligence of the Government as regards implementation and keeping to its promise to devote $10 \%$ of Ghana's GDP to science and technology, there would have been stimulated robust innovations from Ghanaian scientists.

Many of the developing world's poorest farmers and food-insecure people are highly dependent on root and tuber crops as a contribution. Scott et al., (2000) presented global projections of supply, demand, and trade for root and tuber crops to the year 2020. According to the baseline scenario, roots and tubers will decline in relative economic importance only marginally than the other major food and feed crops over the next three decades. The results of their study contrasted with earlier projections that predicted a decline in importance for roots and tubers. In the past, root and tuber crops were overlooked in policy deliberations precisely because their potential was considered more limited than actual growth rates indicate.

Ghana still imports more rice to supplement domestic production. It appears that even with accelerated irrigation and increasing fertilizer supply, this deficit in cereals would remain. However, technological inputs such as improved seeds, which are not adequately captured in our model, could help increase the yield frontier and help meet a part of this deficit in the future. Researchers are therefore encouraged to write good proposals to attract funding to research into less research commodity areas such as cereals and legumes, and biodiversity. This will result in better data collection and publishing.

The decrease in cereals' and legumes were related to the work of Boxall (2001), where the effects of drought co-vary with legume species, soil texture, agro-climatic region, as drought timing remains unclear. To address these uncertainties, they collected literature data between 1980 and 2014 that reported monoculture legume yield responses to drought under field conditions and analysed this data set using meta-analysis techniques. In the face of changing climate, their study provided useful information for agricultural planning and research directions for the development of drought-resistant legume species to improve adaptation and resilience of agricultural systems in the drought-prone regions of the world.

During the thirty-four year-period, a total of 232 publications were produced by researchers in CSIR-Plant Genetic Resources 
Research institutes (CSIR-PGRRI) in Ghana. As revealed in Fig. 2, the number of publication increased from half-decade to the other. The publications ranged from 4 (1981-1990) to 72 (2011-2015). The CSIR-PGRRI Staff publications increased from the first decade but dropped in the fifth decade then increased in the last decade.

The increase in the number of publications may simply be attributed to the number of projects and researchers and technical staff in the CSIR-PGRRI Ghana. Also, the revised senior members' conditions of service (2010) which required 5:7:7 publications from Research Scientist to Chief Research Scientist and "publish or perish" syndrome, especially concerning research-grade staff and academia, have contributed to the increase in research and publications.

According to Louis, et al., (2005) more than 1200 articles related to plant genetic resources were published in journals, reports, and theses since 1983. An exponential increase in the number of publications started in 1960, resulting in an average of 200 publications per five years.

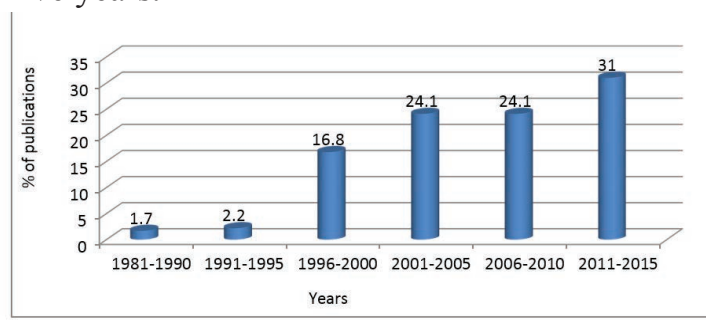

Fig. 2: Number of Publications Source: Authors computation

PGRRI Directory had 349 of the articles published as of December 2015, and these were contributed by staff of the Plant Genetic Resources Research Institute. The remaining 144 of the articles had come from other academia and Plant Genetic Resources managers, the universities and other research institutes in and outside Ghana (Table 2).

The analysis indicated that authors within CSIR-Plant Genetic Resources Research Institute were more than authors outside CSIR-PGRRI. An average of two authors per paper was recorded. An avenue should, therefore, be created for young research scientists to acquire skills in scientific writing as this could enable them to write more manuscripts for publications. The researchers strongly propose regular seminars and workshops on convincing proposal writing for scientists to research into more developmental projects and publish research results.

TABLE 2

Contributions of Authors within and outside CSIR-PGRRI

\begin{tabular}{lll}
\hline Publication of Articles & Articles & $\%$ \\
\hline Authors Within CSIR-PGRRI & 349 & 70.8 \\
Authors Outsiders CSIR-PGR- & 144 & 29.2 \\
RI & & \\
Total number of authors & 493 & 100 \\
Total number of articles & 232 & \\
\hline
\end{tabular}

Source: Field Data (2015)

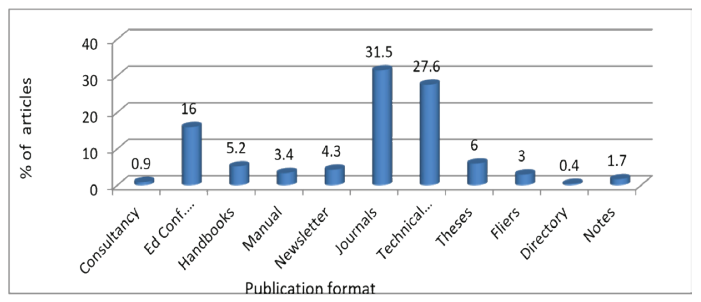

Fig. 3: Number of Publications Source: Authors computation 
The study also shows that authors of Ghana's Plant Genetic Resources (PGR) literature make use of varied forms of publications as indicated in Fig. 3 above. The research-grade staff and technical officers of the institutes are publishing their manuscripts in local and international journals, local bulletins and presentation of papers at conferences and workshops. As in the case of other Bibliometric studies on PGR and information literature, journals and technical reports accounted for more than fifty percent (137) of the total (232) number of publication formats with $58.1 \%$, while Directory recorded the least of the formats with $0.4 \%$. It is interesting to note that Journals and Technical reports were close in terms of the content, an indication of the fact that scholarly journals may be generated from Technical reports in a particular discipline.

Assessment of research output is a stepping stone to understanding the consequences of research, performance and commitment to research activities. Research grade staff members are encouraged to use the appropriate formats for professionalism, consistency, and preparation for potential submission. This is because there are marks for each format of publication for staff career advancement.

TABLE 3

Articles published in journals by staff of CSIR-PGRRI (1981-2015)

\begin{tabular}{llcll}
\hline S/N & Type of Journals published & $\begin{array}{c}\text { Articles } \\
\text { Published }\end{array}$ & $\%$ & Place \\
\hline 1 & Advance Crop Science & 1 & 1.2 & Foreign \\
2 & African Journal of Agricultural Research & 4 & 5 & Foreign \\
3 & Agriculture \& Food Security & 1 & 1.2 & Foreign \\
4 & Agriculture, Forestry and Fisheries & 1 & 1.2 & Foreign \\
5 & Asian Journal of Agricultural Extension, & 1 & 1.2 & Foreign \\
& Economics \& Sociology & & & \\
6 & & & & \\
7 & Capacity Development & 1 & 1.2 & Foreign \\
8 & Entomology Society of America & 1 & 1.2 & Foreign \\
9 & Genet Resource Crop Evol. & 1 & 1.2 & Foreign \\
10 & Ghana Journal of Agricultural Extension and Rural Development & 3 & 4 & Local \\
11 & Ghana Journal of Forestry & 17 & 21 & Local \\
12 & Ghana Journal of Horticulture & 1 & 1.2 & Local \\
13 & Ghana Journal of Human Ecology & 7 & 9 & Local \\
14 & Ghana Journal of Science & 1 & 1.2 & Local \\
15 & International Journal of Agricultural Research and Innovation & 1 & 1.2 & Foreign \\
16 & International Journal of Agricultural, Forestry and Fisheries, & 1 & 1.2 & Foreign \\
17 & International Journal of Biodiversity and Conservation & 1 & 1.2 & Foreign \\
18 & International Journal of Plant Breeding and Genetic & 3 & 4 & Foreign
\end{tabular}




\begin{tabular}{lllll}
19 & Japanese Journal of Crop Science & 3 & 4 & Foreign \\
20 & Journal of Applied Science and Research & 1 & 1.2 & Foreign \\
21 & Journal of Applied Science and Technology & 5 & 6 & Local \\
22 & Journal of Crop Science & 2 & 2.4 & Foreign \\
23 & Journal of Global Economics, Management and Business & 1 & 1.2 & Foreign \\
& Research & & & \\
24 & Journal of Microbiology and Biotechnology Research & 1 & 1.2 & Foreign \\
25 & Journal of the Ghana Science Association & 2 & 2.4 & Local \\
26 & Journal of the KNUST & 1 & 1.2 & Local \\
27 & Nigeria Journal of Natural Products and Medicine & 1 & 1.2 & Foreign \\
28 & PGR Newsletter/ Gene conserve Article Issues & 4 & 5 & Foreign \\
29 & Plant Genetic Resources Centre, Extension Series & 3 & 0.4 & Foreign \\
30 & Scientia Horticulture & 1 & 1.2 & Foreign \\
31 & Springer-Plus & 1 & 1.2 & Foreign \\
32 & Tropical Science & 3 & 4 & Foreign \\
33 & Wageningen Journal of Life Sciences (NJAS) & 2 & 2.4 & Foreign \\
34 & West African Journal of Applied Ecology & 1 & 1.2 & Foreign \\
\hline & Total & $\mathbf{8 2}$ & $\mathbf{1 0 0}$ &
\end{tabular}

\section{Conclusion}

The research indicated varied formats of plant genetic resources publications. The scientific and technical formats of publications were the same style of writing but a different mode of dissemination. Staff of the CSIR-Plant Genetic Resources Research Institute published in 82 journals within the thirty years. An attempt to find out which journals were most popular with Plant Genetic Resources Researchers in Ghana under the study revealed some interesting development. For instance, it was clear that despite the irregular publications of the Ghana Journal of Agricultural Science (GJAS), it recorded the highest number of publications, seventeen articles (Table 3).

Another noteworthy observation was the predominance of Ghana Journal of Horticulture and Journal of Applied Science and Technology which accounted for seven and five articles respectively. Ghana Journal of Forestry, Journal of the KNUST, Agriculture and Food Security recorded the least journal published. The research shows that seventy-five articles were published in thirty-four scholarly journals, comprising nine local and twenty-five foreign journals. Forty-one articles each were published in both local and foreign journals (Tables 2 and3).

The study has shown that the growth of plant genetic resources literature on Ghana is related to the increasing growth of projects and researchers in Ghana. Literature in a subject field is a useful parameter for measuring the growth of that subject. It is therefore expected that as more projects and researchers are produced in the country, there would be more research and publications in plant genetic resources literature on Ghana. Staff members' research output patterns were expressible 
in research output formats and year-wise distributions patterns which show commitment to research activities, dissemination and dispersion of research findings.

\section{Recommendations}

The findings of this research will highlight areas of research undertaken by scientists over the period. This will also help them to know publications emanating from research work undertaken and reviewed in terms of year of publication, commodity group, specific crops, specialization, collaboration and position papers published in a local journal or as foreign. Researchers are motivated to publish more in high reputable impact journals, as well as to be visible to the outside world. Horticulture Division should be created at the CSIR-Plant Genetic Resources Research Institute to research into horticultural and floriculture species, foundation seeds production, agro-processing of some local and exotic fruits under conservation, as well as planting material production for sale.

The study further advocates for Policy brief to be documented after completion of every institutional collaborated project. This will help to build strong linkages and teamwork among the research community in Ghana and beyond. The Policy brief will help in the monitoring and evaluation of future projects.

\section{Acknowledgement}

I thank Dr. L. M. Aboagye, Dr. S. K. Boateng, and Dr. K. Fafa Egbadzor (CSIR-PGRRI) for constructive criticism and useful suggestions on different versions of this paper. I thank the staff of CSIR-PGRRI who allowed their publications to be used for the study.

\section{REFERENCES}

Aboagye, L. M. (2001) Notes on plant genetic resources management. Basic Terminology, pp. $1-8$.

AIC (2011) Final Report for the AIC International Twinning Partnership Program, pages 24 - 32. Retrievable from http://aic.ca.previewmysite.com/wp-content/uploads/2015/ aic_itpp_program_report_2011.pdf

Alemna, A. A. (1994) Scholarly publishing at the University of Ghana 1976-1986. Implementing for academic library development. International Journal of Information and Library Research. 6 (3), $159-177$.

Ayitey, S. (2011) The role of root and tuber crops in the socio-economic and industrial development of West Africa. West Africa Agricultural Productivity Program International Root and Tuber Crops Conference held at Mensvic Hotel, in Accra, Ghana

Boxall, R. A. (2001). Post-harvest losses to insects-a world overview. International Bioterioration and Biodegradation, 48(1-4), 137 - 152. Available at www.scopus.com

Bissah, M. N. (2015). In-vitro establishment of Cryptolepis Sanguinolenta (Nibima), pp. $1-24$. CSIR-PGRRI/TR/BMN/2015/64

El-Maamiry, A. A. \& Ghauri, M. A. (2013) Measuring information quality: Concerns on the use of bibliometric studies. International Journal of Information Dissemination and Technology. 3 (4), $274-278$.

Fosu, V. K. \& Alemna, A. A. (2002) Fifty years of library literature on Ghana: A Bibliometric. Ghana Library Journal 14, 1 - 5. ISSN 08553033

Gautam, V. K. \& Mishra, R. (2015) Scholarly research trend of Banaras Hindu University during 2004-2013: A scientometric study 
based on Indian citation index. Journal of

Library \& Information Technology, 35 (2), 75 - 81 DOI: $10.14429 /$ djlit.35.2.8021

Harms, K. E., Condit, R., Stephen P., Hubbell, S. P. \& Foster, R. B. (2004) Habitat associations of trees and shrubs in a 50-ha neotropical forest plot. Journal of Ecology. Obtainable from https://doi.org/10.1111 /j.1365-2745.2001.00615

Harande, Y. I. \& Ibrahim, A. U. (2014) A bibliometric analysis of three Countries in different world regions. Journal of Library and Information Sciences 2 (1), 49 CAmerican Research Institute for Policy Development www. aripd.org/jlis Basic Literature of Diabetes.

Hassan, U. I., Haddawy, P., Kuinkel, P., Degelsegger, A. \& Blasy, C. (2012) A bibliometric study of research activity in ASEAN related to the EU in FP7 priority areas Saeed. Scientometrics 91, 1035 - 1051. Obtainable from DOI 10.1007/s11192-012-0665-1.

Kevin, S. (2008) Starting a new scholarly journal in Africa. Creative Commons, 559 Nathan Abbott Way, Stanford, California 94305, USA, $1-58$.

Krippendorff, K. (2004) Content Analysis: An Introduction to Its Methodology: Book Review: (2nd ed.). Thousand Oaks, CA: Sage.

Louis, W., Dekker, A. B., Klaas, O. A. \& Coen, J. (2005) Exponential increase of publications related to soil water repellency. Australian Journal of Soil Research 43, 403 - 441.

Murison, E., \& Webb, C. (1991) Writing a research paper: Writing practice for University Students, Learning Assistance Centre, University of Sydney. Obstetrics and Gynaecology Forum, 1 - 2. Available at http://www.ajol.info/ journal_index.php?jid=202) and Journal of Social Aspects of HIV/AIDS.
Osei-Kofi, P. S. (2015) Journals in the Council for Scientific and Industrial Research (CSIR) Ghana: Trend, challenges and the future. $A$ thesis submitted to the Department of Publishing Studies, Kwame Nkrumah University of Science and Technology, Kumasi in partial fulfillment of the requirements for the degree of Master of Art in Publishing, $1-81$.

Osei-Kofi, P. S. (2015) PGRRIREF Directory, 1 - 43.

Pautasso, M. (2013) Ten simple rules for writing a literature review. PLoS Comput Biol 9(7), e1003149.https://doi.org/10.1371/journal. pcbi.1003149

Prasad, S. K., Pullabhotla, H. G. \& Kumar, A. (2011) New Delhi; International Food Policy Research Institute Supply and demand for cereals in Nepal, 2010 - 2030.

Rudebjer, et al. (2012) On the topic, beyond commodity crop: Strengthening young scientists' capacity for research on underutilized species in Sub-Saharan Africa. Proceeding of $2^{\text {nd }}$ International Symposium on Underutilized Plant Species, Eds: Massawe, F., et al. Acta Hort, 979, ISITS, $577-587$.

Salifu, A. B. (2011) The role of root and tuber crops in the socio-economic and industrial development of West Africa. West Africa Agricultural Productivity Program International Root and Tuber Crops Conference held at Mensvic Hotel, in Accra, Ghana.

Sam, J. (2008) An analysis of Ghana Library Journal: A bibliometric study. African Journal of $\mathrm{Li}$ brary, Archives and Information Science 18(1), 67.

Scott, G. J., Rosegrant. M. W. \& Ringler, C. (2000) Global projections for root and tuber crops to the year 2020. Food Policy 25 (5), 561 - 597. 